\title{
ANÁLISE DO BLENDED LEARNING NO CURSO DE GRADUAÇÃO EM ENGENHARIA DE PRODUÇÃO NA MODALIDADE EAD DE UMA INSTITUIÇÃO DE ENSINO DO MUNICÍPIO DE LONDRINA.
}

\author{
LONDRINA/PR MAIO/2018
}

\author{
Edson Augusto Lopes ～- UNOPAR - edson.augusto.lopes@gmail.com \\ Tipo: Relato de Experiência Inovadora (EI) \\ Categoria: Conteúdos e Habilidades \\ Setor Educacional: EDUCAÇÃO SUPERIOR
}

\begin{abstract}
RESUMO
Atualmente o ensino veem utilizando a tecnologia como ferramenta na melhoria da aprendizagem $e$ práticas pedagógicas, principalmente no uso em instituições de ensino superior. Esta integração entre tecnologia e metodologia pedagógica fortalece a transformação e facilita o aprendizado do estudante. Nos cursos de graduação em engenharia a distância de uma instituição de ensino da cidade de Londrina, foi adotado a abordagem blended learning como proposta de diferencial para os alunos, professores, e comunidade, com o objetivo de inovar na modalidade de ensino, reduzindo o distanciamento entre cursos somente presenciais ou cursos somente na modalidade EAD. Diante desta proposta, e com base em outros autores que abordam o blended learning o objetivo deste artigo consiste em apresentar os resultados de aplicação após o lançamento ocorrido no ano de 2016, com base nas teorias apresentadas e levantamento descritivos do curso de Engenharia de Produção em EAD desta instituição,avaliando se o termo blended learning pode ser considerado como modelo acadêmico adotado no curso.
\end{abstract}

Palavras-chave: Blended learning, ensino híbrido, engenharia de produção 


\section{INTRODUÇÃO}

O estudo a distância surgiu como diferencial nos últimos anos, a facilidade de acesso e o apoio através de plataformas em EaD, conhecido como ambiente AVA tem propiciado ao discente, meios de acesso para a sua formação acadêmica.

A dificuldade do discente torna-se maior quando são apresentadas disciplinas que exigem o conhecimento matemático, físico e químico, dificultando o entendimento e o aproveitamento teórico.

Esta característica está representada no modelo de ensino existente em EaD, ou seja, os alunos possuem o comportamento de receptores da informação, comum na sala de aula tradicional, e constituído de um modelo ultrapassado, ou seja, os estudantes estão condicionados ao aprendizado e absorção da informação somente através do professor.

Como alternativa, surgiram diversas propostas de práticas pedagógicas, como a Aprendizagem Baseada em Problemas (ABP), ou a Aprendizagem Baseada em Problemas e por Projetos (ABPP), Valente (2014) reforça que a ABP é de difícil aplicação pois há a necessidade considerar o currículo que está sendo trabalhado em relação ao problema proposto e o nível de conhecimento dos alunos, em relação a ABPP, há a dificuldade de escolher o tema de trabalho, devido a diversidade e a necessidade do professor mediar o processo de aprendizagem, em resumo ambas são difíceis de serem implantadas em salas com um grande número de alunos.

Estas dificuldades podem ser consideradas no âmbito da aprendizagem presencial, porém com o avanço de tecnologias digitais de informação e comunicação, tais barreiras foram transpostas, permitindo ao professor e ao aluno a utilização de ambientes virtuais para determinadas aprendizagens.

Esta integração das tecnologias de informação e comunicação nas atividades de sala ficou conhecido como blended learning ou ensino hibrido, sendo atualmente utilizado por algumas instituições de ensino superior, destinando conforme portaria 4.059, de 10 de dezembro de 2004 a introdução de disciplinas no modo semipresencial em até $20 \%$ da carga horária total de cursos superiores reconhecidos. (DIAS, ORTH, MANGAN, 2011).

O blended learning é uma modalidade de aprendizagem também conhecida como, b-learning, "buscando combinar práticas pedagógicas do ensino presencial e do ensino a distância, com o objetivo de melhorar o desempenho dos alunos em ambos os ensinos. " (ESPÍNDOLA, 2016) 
Embora, este modelo não seja novidade no meio acadêmico, a primeira aplicação ocorreu em 1996 na Miami University (Ohio, EUA) na disciplina de Microeconomia, conforme Valente (2014), obtendo como resultado ganhos significativos na compreensão conceitual, bem como habilidades para resolver problemas comparáveis aos adquiridos em estudo on-line, principalmente em disciplinas das áreas de exatas.

Considerando a existência de quatro variações de ensino híbrido, o modelo virtual enriquecido é o que apresenta maior relação com o curso de Engenharia de Produção ofertado como curso-piloto deste novo modelo de ensino, por uma instituição de ensino no município de Londrina.

E através da vivência como aluno no curso de Engenharia de Produção surge a necessidade de avaliar e apresentar através de um relato de experiência, uma análise da aplicação do modelo blended learning, visando contribuir na melhoria do processo pedagógico da instituição e do curso de graduação em Engenharia de Produção.

\section{OBJETIVOS}

O objetivo principal consiste em analisar a metodologia blended learning do curso de graduação em Engenharia de Produção na modalidade EaD de uma instituição de ensino do município de Londrina. Para o alcance do proposto, serão necessários alguns objetivos específicos, sendo:

a. Realizar estudo bibliográfico da metodologia blended learning;

b. Levantar as atividades práticas apresentadas no curso desde o $1^{\circ}$ semestre até 0 momento;

c. Analisar as atividades realizadas na instituição em relação a metodologia estudada;

d. Apresentar o resultado da análise.

\section{REFERENCIAL TEÓRICO}

A utilização da metodologia blended learning surgiu com o avanço das tecnologias de informação e comunicação como meio de aprendizagem continuada do aluno, visto que, o que aprendia em sala de aula na modalidade presencial, poderia ser expandida em relação ao espaço e tempo de estudo, permitindo a este aluno aprofundar o seu conhecimento através destas tecnologias.

O conceito blended learning não ser uma abordagem recente, pois os educadores 
utilizavam de recursos como áudio e vídeo para as atividades em ambiente de sala de aula, visando a variedade de atividades e proporcionando melhoria e complementação pedagógica para o estudante.

E atualmente por haver novas tecnologias, este modelo vem se destacando massivamente entre as instituições com características de ensino presencial, utilizandose de estratégias para que o aluno possa complementar determinadas disciplinas em um ambiente virtual.

Desta forma, Gomes e Melo (2013), apresentam o blended learning em dois cenários, sendo:

a. Classroom Learning: o emprego de tecnologias digitais, como áudio, víedo, internet, jogos digitais, vídeos, entre outros em sala de aula para a solução de problemas, trabalho em equipe dentro de um contexto proposto;

b. Online Learning: a aprendizagem online através de ambiente virtual de aprendizagem, com acesso aos conteúdos e ferramentas de interatividade e aprendizagem.

Para Tori (2009), o blended learning é uma evolução dos sistemas de aprendizagem virtual interativa e convergência com a aprendizagem presencial, ou seja, no passado a predominância era da aprendizagem presencial, com separação clara entre presencial e virtual, onde atualmente há uma expansão do sistema de aprendizagem virtual interativo, ocorrendo a aproximação com a aprendizagem presencial ocorrendo uma crescente expansão do blended learning, que no futuro terá predominância sobre os dois sistemas que o originou.

Conforme Silva (2015), percebe-se que as explicações anteriores se referem a cursos presenciais com a adoção de tecnologias, permitindo que o aluno desta modalidade possa também aprofundar seus estudos a distância. Nota-se esta atividade através da portaria publicada pelo Ministério da Educação (MEC), em sua portaria n. 04.059 , de 10 de dezembro de 2004, autorizando as Instituições de Ensino Superior (IES) a incluírem, na organização pedagógica e curricular de cursos em nível superior reconhecidos, até vinte por cento de cursos/disciplinas, no ensino semipresencial.

Para ensino semipresencial entende-se que são cursos ofertados em formato presencial e a distância, sendo que conforme portaria do MEC para os cursos presenciais, $20 \%$ poderá ser realizado à distância e para os cursos EAD, não há um limite de $20 \%$, porém entende-se que é semipresencial, pois o aluno necessita participar presencialmente das 
aulas e realização de provas.

Desta forma, a integração de modalidade EAD com partes da modalidade presencial (laboratórios ou práticas), conforme Horn e Staker (2015), podem ser definidas como modelo Flex, onde um curso ou disciplina online é principal para a aprendizagem, mesmo que às vezes direcione para atividades presenciais.

\section{PROCEDIMENTOS METODOLÓGICOS}

O presente estudo tem por metodologia de aplicação um estudo bibliográfico do tema, utilizando-se de uma quantidade de informações existentes, permitindo entendimento do assunto, visto que, o contato com o objeto de estudo encontra-se apenas na prática, no papel do aluno, e não como pesquisador. (MASCARENHAS, 2012)

A pesquisa bibliográfica pode ser realizada independentemente ou como parte da pesquisa descritiva ou experimental [...] a pesquisa possui características descritiva, visto que, procura-se observar, registrar, analisar e correlacionar fatos ou fenômenos (variáveis) sem manipulá-los. (CERVO, 2007).

Desta forma, conforme citado anteriormente, o uso da pesquisa bibliográfica e a pesquisa descritiva permitem discorrer sobre o assunto e encontrar respostas tanto para o objetivo principal, quanto para os objetivos específicos apresentados neste estudo.

A metodologia utilizada propõe um levantamento das atividades práticas ofertadas pela instituição, sendo avaliada de forma qualitativa a aplicação e resultado por parte de experiência própria do autor, ou seja, a aplicação do método permite concluir se a metodologia blended learning é aplicada no curso de Engenharia de Produção ou se a aprendizagem não possui apenas características de aplicação de tecnologias da informação e comunicação na educação, denominada como online learning conforme apresentado no referencial teórico por Melo e Gomes.

Estas atividades são apresentadas no Guia de Percurso do curso, disponível no site da instituição, onde são postadas as atividades práticas a serem ofertadas no Semestre. Conforme Catarino (2017), o modelo acadêmico KLS 2.0 desta instituição, adota a abordagem blended learning com a proposta metodológica da sala de aula invertida, para os alunos ingressantes em 2016 nos cursos EAD. Este modelo com base na sala de aula invertida compreende três momentos didáticos, sendo a pré-aula, a aula mediada (teleaula) e a pós-aula (aula atividade). 
A tabulação a ser realizada consiste em aplicar uma análise de porcentagem de "disciplinas práticas" existente no rol de disciplinas ofertadas pelo curso.

\section{APRESENTAÇÃO E DISCUSSÃO DOS RESULTADOS}

Em análise das disciplinas ofertadas pelo curso e àquelas denominadas disciplinas práticas, verifica-se no gráfico 1 , um resultado de $21 \%$ do total das disciplinas possui a prática em suas ementas e programas pedagógico.

Realizando a mesma análise, porém, considerando a carga horária das disciplinas em comparação com a presença efetiva do aluno em atividades presenciais, verifica-se através do gráfico 2 uma diminuição nesta representatividade das disciplinas práticas, passando para $15 \%$ em relação a carga horária total das disciplinas.

Gráfico 1 - Disciplinas práticas em relação ao total ofertado (quantidades de disciplinas)

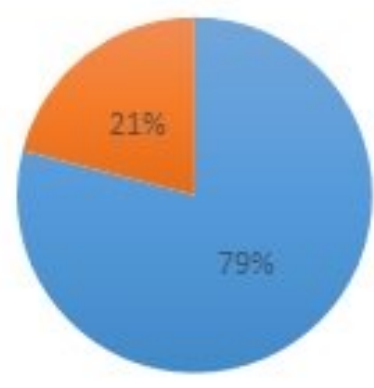

- Disciplinas ofertadas

- Disciplinas práticas

Gráfico 2 - Disciplinas práticas em relação ao total das disciplinas (carga horária)

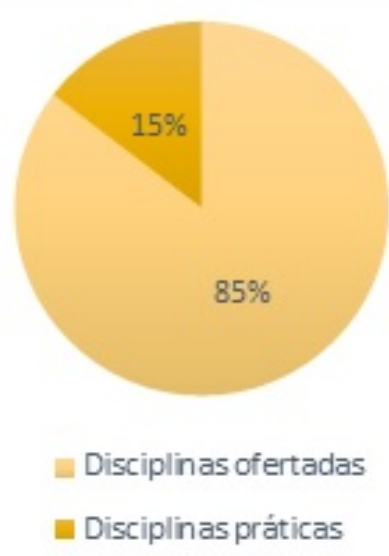

E se considerarmos a carga horária total do curso, verificamos que as 
representatividades das disciplinas práticas correspondem a $3 \%$ de acordo com 0 gráfico 3.

Como análise dos resultados apresentados pelos gráficos, verifica-se que em todos há a aplicação da metodologia blended learning, uma vez que a mesma não especifica uma porcentagem mínima necessária para caracterização.

Gráfico 3 - Disciplinas práticas em relação ao total ofertado (carga horária do curso)

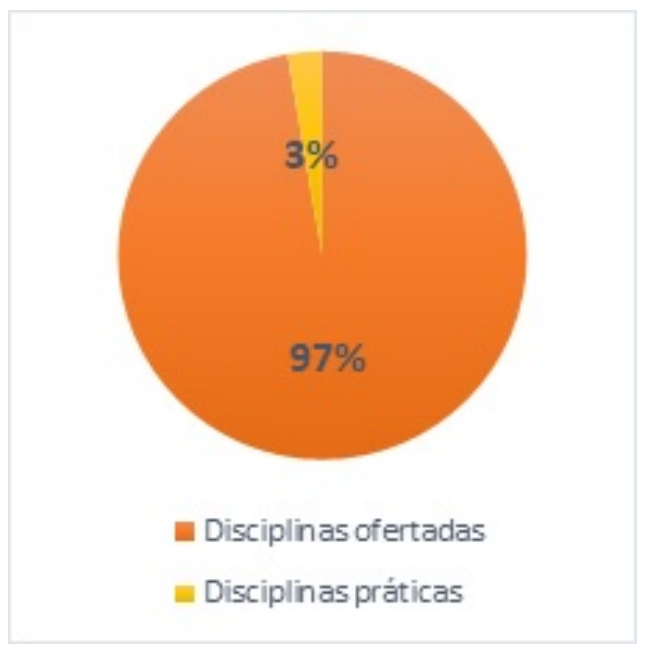

Porém, ao analisarmos como diferencial ou inovação de aplicação da modalidade, o mesmo não possui representatividade significativa de inovação, pois o aluno durante os 10 semestres do curso, visualiza a teoria aplicada através das práticas ofertadas somente $3 \%$ da carga horária proposta, tendo pouca contribuição no desenvolvimento, pois conforme Belhot (2005) em pesquisa realizada com 123 alunos, o mesmo aponta que $60 \%$ dos estudantes classificados como "ativos" preferem atividades práticas juntamente com $72 \%$ dos "sensoriais" que são adeptos aos trabalhos manuais, como por exemplo, aulas em laboratório, onde as mesmas resultam em benefícios de aprendizagem em relação ao estilo de aprendizagem.

\section{CONSIDERAÇÕES FINAIS}

A inserção de novas tecnologias veem alterando as metodologias e práticas pedagógicas de ensino, entre elas a adoção do método denominado blended learning. Devido a falta de regras e ou indicadores percentuais, a teoria considera como metodologia blended learning a "mistura" de ensino presencial e ensino virtual, onde, conforme pesquisa apresentada neste artigo, a inserção de $3 \%$ de atividades presenciais como o uso de laboratórios e ou práticas de disciplinas podem ser consideradas, porém sem uma comprovação de melhoria para o aluno em relação ao 
desenvolvimento do seu conhecimento.

Desta forma, torna-se interessante para o uso desta metodologia um fator de referência entre porcentagens aceitáveis de ensino, bem como estudos mais aprofundados sobre os benefícios advindos em determinadas taxas, visando determinar uma quantidade mínima de ensino "híbrido" nas instituições.

\section{REFERÊNCIAS}

BELHOT, Renato Vairo; FREITAS, Alessandra A.; DORNELLAS, Danielle V. Benefícios do conhecimento dos estilos de aprendizagem no ensino de engenharia de produção. In: Congresso Brasileiro de Ensino de Engenharia. 23, Campina Grande, 2005.

CATARINO, lolanda Claudia Sanches. et al. Blended learning como prática pedagógica nos cursos de graduação de engenharia - modalidade EAD. In: Congresso Internacional ABED de Educação a Distância. 23, Foz do Iguaçu, 2017.

CERVO, Amado Luiz. Metodologia científica. 6.ed.São Paulo: Pearson Prentice Hall, 2007.

ESPÍNDOLA, Rafaela. O que é e como funciona o blended learning? Disponível em: https://www.edools.com/blended-learning/. Acesso em: 18 mar. 18.

HORN, M. B.; STAKER, H. Blended: usando a inovação disruptiva para aprimorar a educação. Tradução: Maria Cristina Gularte Monteiro. Porto Alegre: Penso, 2015.

LITTO, Fredric Michael;FORMIGA, Manuel Marcos Maciel (orgs.). Educação a distância: o estado da arte. São Paulo: Pearson Education do Brasil, 2009.

LITTO, Fredric Michael;FORMIGA, Manuel Marcos Maciel (orgs.). Educação a distância: o estado da arte, volume 2. 2.ed. São Paulo: Pearson Education do Brasil, 2012.

MASCARENHAS, Sidnei Augusto. Metodologia Científica. São Paulo: Pearson Education do Brasil, 2012.

MELO, Jeane C.B.;GOMES, Tancicleide C.S.O pensamento computacional no ensino médio: uma abordagem blended learning. In: V Congresso Brasileiro de Informática na 
Educação (CBIE 2016), 2016, Departamento de Estatística e Informática - Universidade Federal Rural de Pernambuco (UFRPE), Recife, 2013.

SILVA, Michele Rejane Coura; MACIEL, Cristiano. Blended learning: reflexões sobre o ensino semipresencial na educação superior no Brasil. In: XII Congresso Nacional de Educação (EDUCERE), Pontifícia Universidade Católica do Paraná, Curitiba, 2015

VALENTE, José Armando. Blended learning e as mudanças no ensino superior: a proposta da sala de aula invertida, Brasil, Educar em Revista, Curitiba, Edição Especial n. 4/2014, p. 79-97. Editora UFPR. 